\title{
Effects of photoperiod and social variables on reproduction and growth in the male musk shrew (Suncus murinus)
}

\author{
N. L. Wayne and E. F. Rissman \\ Departments of Biology and Psychology, University of Virginia, Charlottesville, VA 22901, USA
}

\begin{abstract}
Summary. In Exp. 1, the time course for the photoperiodic response in juvenile male musk shrews was examined by exposing animals to short (10L:14D) or long (14L:10D or 18L:6D) daylengths for 10, 20, 40 or 56 days. When compared with the response of animals maintained in long days, those exposed to short days showed an inhibition of reproductive maturation by 40 days of treatment. In Exp. 2, the combined effects of photoperiod and social cues were investigated in juvenile males that were either housed in short days (with or without a female) or in long days (with or without a female) for 40 days. The short photoperiod was generally inhibitory to sexual maturation, while the presence of an adult female was generally stimulatory, i.e. animals living with a female in long days had the greatest level of sexual maturity, while those living alone in short days had the lowest level of maturity. Animals that received opposing signals, i.e. short days in the presence of a female, had an intermediate response which was equivalent to the response seen in males living alone in long days. These results suggest that the presence of a female can partly reverse inhibitory effects of short days. In Exp. 3, the effects of photoperiod and social cues on the reproductive physiology of the adult male (same design as in Exp. 2) were investigated. The results show that the adult male musk shrew is responsive to both photoperiodic and social cues, in a manner similar to that of juvenile animals. Overall, these studies suggest that photoperiod and social cues have independent, as well as integrative, effects on reproduction in this tropical insectivore.
\end{abstract}

Keywords: musk shrew; photoperiod; puberty; reproduction; social cues

\section{Introduction}

Much of our information on regulation of reproduction by environmental factors comes from work on seasonally breeding animals residing within the northern temperate zone. In these animals, photoperiod is the most commonly used (and investigated) external cue for synchronizing reproduction to the optimal time of year (Turek \& Campbell, 1979). However, most species of mammals inhabit tropical regions and yet there is little information on the reproductive biology of these animals (Bronson, 1985). Unlike animals residing in the temperate zone, those living in the tropics are not subject to large seasonal swings in photoperiod or temperature, although many tropical animals are exposed to changes in other external factors such as rainfall and food availability. Therefore, as with seasonal breeders, it is also important for tropical animals to initiate breeding at times when reproductive success will be maximized.

The work presented in this paper concerns environmental regulation of reproduction in the male musk shrew (Suncus murinus), an insectivore which inhabits tropical and subtropical regions throughout Asia. Although this species breeds opportunistically and pregnant females and fertile males can be found throughout the year (Harrison, 1955; Barbehenn, 1962; Louch, 1966; Beg et al., 
1986), small seasonal peaks in reproductive activity have been documented in some locations. For instance, peak reproductive activity in Malaya occurs in the autumn (Harrison, 1955), while peak breeding activity in Guam and Pakistan occurs in the spring-summer (Barbehenn, 1962; Beg et al., 1986). Rissman et al. (1987) showed that exposure to a short photoperiod inhibited reproductive function in juvenile male musk shrews, while the presence of an adult female stimulated sexual maturation in the male musk shrew (Rissman et al., 1990). Our primary aim in the present experiments was to investigate the effects of photoperiod and social cues presented simultaneously on sexual maturation in the male musk shrew. We also investigated the effects of these cues on reproduction in adult males.

\section{Materials and Methods}

General. The animals used in these studies were born and raised in our colony at the University of Virginia. The original stock was provided by Dr G. L. Dryden in 1985 and descended from animals trapped in the early 1960s on Guam Island at a latitude of $13^{\circ} \mathrm{N}$. Musk shrews were born into and raised in a light-dark cycle of $14 \mathrm{~h} \mathrm{light:10 \textrm {h } \text { dark }}$ (14L:10D; lights on at 07:00 h EST) at $23 \pm 1^{\circ} \mathrm{C}$. Water and food (a mixture of Purina cat chow and mink chow from Milk Speciality, New Holstein, WI, USA) were provided ad libitum. In all studies, treatment groups were kept in separate light-tight boxes $(0.48 \times 1.8 \times 0.6 \mathrm{~m})$ with forced ventilation and a single 40 -W cool white fluorescent bulb (1000 lux at cage top); separate timers controlled lights on and lights off in each box. Animals were housed in cages $(28 \times 17 \times 12 \mathrm{~cm})$, and cohabiting males and females in Exps 2 and 3 were given plastic nest boxes $(8 \times 8 \times 6 \mathrm{~cm})$. All animals were weaned at 20 days of age. In all studies, males were assigned to treatment groups based on body weight (to ensure equivalent initial body weights in all groups).

In all experiments, the level of reproductive function was assessed by the relative weights of various androgensensitive target tissues (the seminal vesicle-prostate complex, one anipulla, one flank pad, one testis). At the end of each experiment, animals were anaesthetized with halothane (2-bromo-2-chloro-1,1,1-trifluorethane; Halocarbon Labs Inc., Hackensack, NJ, USA) and rapidly killed by cervical dislocation. Androgen target tissues were then dissected out and weighed. Sperm numbers were calculated from one testis (Kirton et al., 1967).

Experiment 1. In previous studies, short-day inhibition of sexual maturation was evident by 76 days of age ( 56 days of treatment; Rissman et al., 1987). The present experiment was conducted to determine the time course for the effects of photoperiod on reproductive maturation in the male. The 20-day-old males were assigned to one of three treatment groups. A control group was maintained in 14L:10D (preweaning photoperiod). One experimental group experienced a 4-h decrease in photoperiod to 10L:14D to determine the time course of suppressive effects of short days. The other group experienced a 4-h increase in photoperiod to 18L:6D to determine the time course of any stimulatory effects of a 'super-long' day. Body weights were recorded on the first day of the study and every 5 days thereafter. From each group, 5-8 animals were killed after $0,10,20,40$ or 56 days of treatment for determination of level of sexual maturity (a total of 13 groups). Animals were assigned to these different treatment times at weaning.

Experiment 2. We considered that the stimulatory effects of cohabitation with a female might override inhibitory effects of short days. To test this hypothesis, 20-day-old males $(\mathrm{N}=40)$ were divided into 4 groups. Half the males were maintained on 14L:10D and the other half were switched to 10L:14D. Half of the males in these 2 groups were housed alone or with an adult female ( $>60$ days of age). Females were ovary intact and were sexually experienced. Body weights were recorded on the first day of the study and every 5 days thereafter. After 40 days, males were killed for determination of level of sexual maturity.

Experiment 3. The purpose of this experiment was to determine whether the reproductive system of adult males is responsive to independent and combined effects of photoperiod and social cues. Body weights were recorded on the first and last days of the study. The design of this experiment was identical to that of Exp. 2, except that adult males were used ( 60 days of age).

Analysis of data. The weights of the androgen-sensitive target tissues were analysed using analysis of covariance with body weight being the covariate. This procedure eliminates any influences of body weight from the analysis. To determine main effects of treatment, one-way or two-way analyses of variance were applied when appropriate, followed by comparisons of group means. In Exp. 1, comparisons of group means were made with the StudentNewman-Keuls multiple-range test. In Exps 2 and 3, comparisons of group means were made with Scheffe's multiple comparison procedure. Body weight data in Exp. 2 were analysed by analysis of variance with repeated measures. Because the relationship between reproductive organs and body weights is not a simple proportional one, we have chosen to present raw, unadjusted tissue weights in the figures. A significant alpha of $P<0.05$ was used. 


\section{Results}

\section{Experiment 1: time course of photoperiodic effects in juveniles}

In general, exposure to $10 \mathrm{~h}$ light/day had a suppressive effect on the reproductive physiology of the juvenile shrew by 40 days of treatment. The main effects of photoperiod on the weights of the androgen-sensitive target tissues, sperm count and body weight are shown in Table 1, while specific differences between group means are indicated in Fig. 1. There were no main effects of photoperiod until 20 days of treatment when there was a significant effect on seminal vesicle-prostate complex weight. By 40 days of treatment there were significant effects of photoperiod on the weights of the seminal vesicle-prostate complex, flank pad and ampulla. However, by 56 days of treatment these main effects of photoperiod were no longer evident, probably because of the appearance of a significant effect of photoperiod on body weight (see 'Materials and Methods', analysis of data for explanation of factoring out the effects of body weight on reproductive organ weight). There were no main effects of photoperiod on testis weight or the number of spermatozoa/testis at any time point during the study.

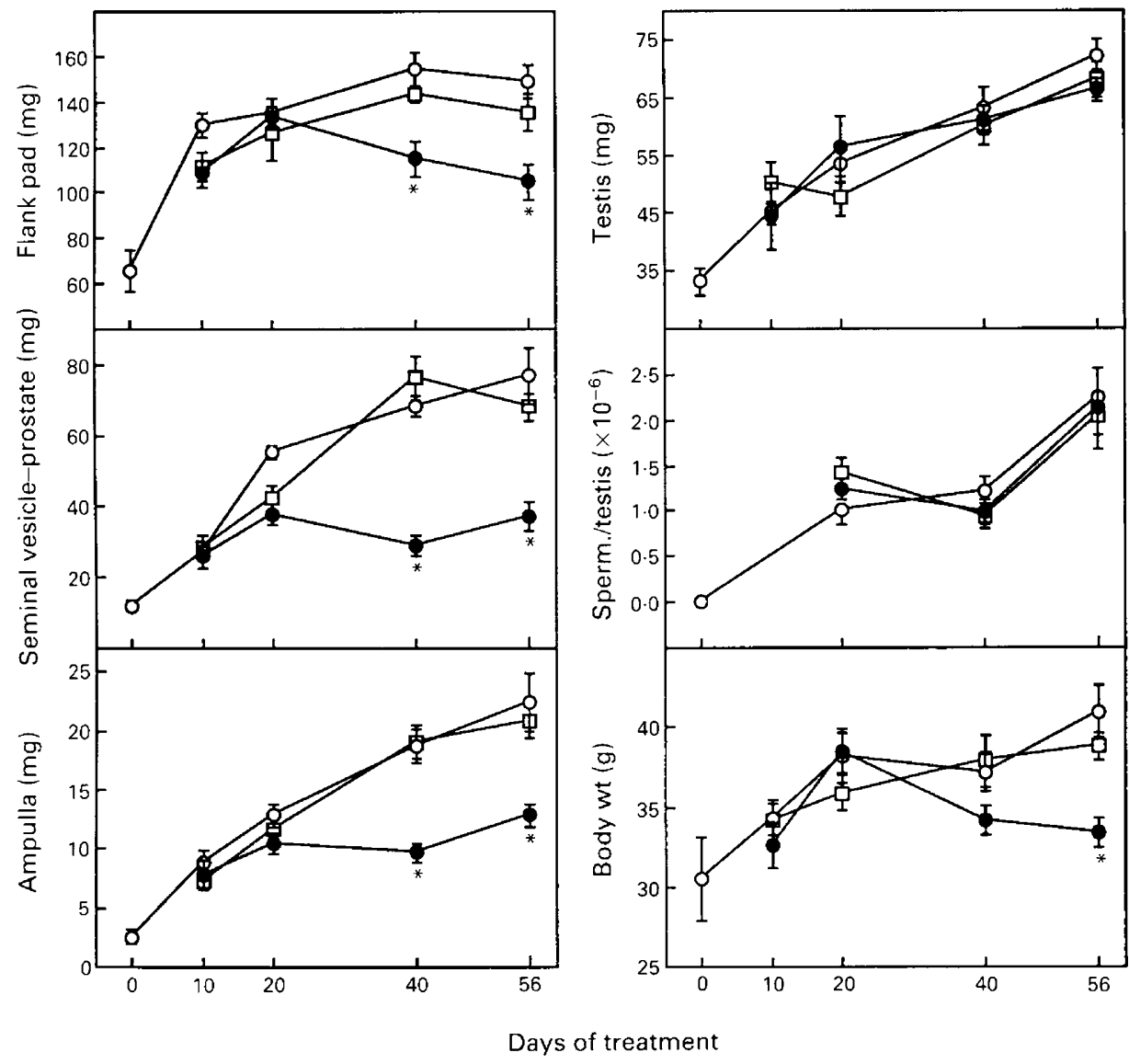

Fig. 1. Values for the weights of the androgen-sensitive target tissues, sperm count and body weight from Exp. 1 are shown as the mean \pm s.e.m. Males were placed into treatment groups at weaning (20 days of age). $\bigcirc, 14 \mathrm{~L}: 10 \mathrm{D} ; \square, 18 \mathrm{~L}: 6 \mathrm{D} ; 0,10 \mathrm{~L}: 14 \mathrm{D}$. ${ }^{*} P<0.05$ compared with other 2 groups. $\mathrm{N}=5-8$ animals per group. 
Table 1. Analysis (F values, with $P$ values in parentheses) of main effects of photoperiod in juvenile males (Exp. 1)

\begin{tabular}{lllll}
\hline & Day 10 & \multicolumn{1}{c}{ Day 20} & \multicolumn{1}{c}{ Day 40} & Day 56 \\
\hline Seminal vesicle- & & & & \\
$\quad$ prostate complex wt & 0.06 (NS) & $14.84(P<0.001)$ & $29.48(P<0.001)$ & $2.26(\mathrm{NS})$ \\
Ampulla wt & 0.69 (NS) & 1.28 (NS) & $13.19(P<0.001)$ & $1.31(\mathrm{NS})$ \\
Flank pad wt & 3.48 (NS) & 0.05 (NS) & $7.41(P<0.01)$ & $0.75(\mathrm{NS})$ \\
Testis wt & 0.58 (NS) & 0.68 (NS) & $0.42(\mathrm{NS})$ & 0.49 (NS) \\
Sperm count & no data & 0.00 (NS) & $1.90(\mathrm{NS})$ & $1.14(\mathrm{NS})$ \\
Body wt & 0.62 (NS) & 0.99 (NS) & $2.33(\mathrm{NS})$ & $11.86(P<0.001)$ \\
\hline
\end{tabular}

Comparison of group means revealed that by 20 days of treatment the seminal vesicle-prostate complex was lighter in animals exposed to $10 \mathrm{~L}: 14 \mathrm{D}$ than those animals kept in $14 \mathrm{~L}: 10 \mathrm{D}$ or $18 \mathrm{~L}: 6 \mathrm{D}$; tissue weights were also lighter in animals kept in 18L:6D than those held on 14L:10D. By 40 days of treatment, the seminal vesicle-prostate complex, flank pad and ampulla were lighter in the group in 10L:14D than in those in 14L:10D and 18L:6D; however, there were no significant differences between the 2 long-day groups. Although there were no main effects of photoperiod on reproductive organ weights by 56 days of treatment, analysis of group means showed that the seminal vesicle-prostate complex, flank pad and ampulla were lighter in the 10L:14D group than in the other two groups, with no significant differences between the 2 long-day groups. Furthermore, body weights of animals held in 10L:14D were lighter than those kept in 14L:10D and 18L:6D, and, again, there was no significant difference between the 2 long-day groups.

\section{Experiment 2: combined effects of photoperiod and social cues in juveniles}

In general, exposure to $10 \mathrm{~h}$ light/day had inhibitory effects and the presence of an adult female had stimulatory effects on both the reproductive physiology and body growth of juvenile males. The main effects of photoperiod and social cues on the weights of the androgen-sensitive target tissues, sperm count and body weight are shown in Table 2, while specific differences between group means are indicated in Fig. 2 (reproduction) and Fig. 3 (body growth). There were main effects of photoperiod and social cues on the weight of the seminal vesicle-prostate complex, but no interaction between these 2 variables. There were also main effects of social cues and age on body weight, with interactions between social cues and age and between photoperiod and age.

Table 2. Analysis (F values, with $P$ values in parentheses) of main effects of photoperiod and social cues in juvenile males (Exp. 2)

\begin{tabular}{|c|c|c|c|c|c|c|}
\hline & \multirow{2}{*}{$\begin{array}{l}\text { Photoperiod } \\
\text { (PH) }\end{array}$} & \multirow{2}{*}{$\begin{array}{l}\text { Social cues } \\
\quad \text { (SC) }\end{array}$} & \multirow{2}{*}{$\begin{array}{l}\text { Age } \\
\text { (A) }\end{array}$} & \multicolumn{3}{|c|}{ Interactions } \\
\hline & & & & $\mathrm{PH} \times \mathrm{SC}$ & $\mathrm{PH} \times \mathrm{A}$ & $\mathrm{SC} \times \mathrm{A}$ \\
\hline $\begin{array}{l}\text { Seminal vesicle- } \\
\text { prostate complex wt }\end{array}$ & $\begin{array}{c}22.79 \\
(P<0.001)\end{array}$ & $\begin{array}{c}12.31 \\
(P<0 \cdot 01)\end{array}$ & - & $\begin{array}{l}1.47 \\
\text { (NS) }\end{array}$ & - & - \\
\hline Ampulla wt & $\begin{array}{r}2 \cdot 60 \\
\text { (NS) }\end{array}$ & $\begin{array}{r}2 \cdot 31 \\
\text { (NS) }\end{array}$ & - & $\begin{array}{l}2.50 \\
\text { (NS) }\end{array}$ & - & - \\
\hline Flank pad wt & $\begin{array}{r}0.23 \\
\text { (NS) }\end{array}$ & $\begin{array}{r}0.03 \\
(\mathrm{NS})\end{array}$ & - & $\begin{array}{l}0.00 \\
(\mathrm{NS})\end{array}$ & - & - \\
\hline Testis wt & $\begin{array}{r}3 \cdot 25 \\
(\mathrm{NS})\end{array}$ & $\begin{array}{r}1.27 \\
(\mathrm{NS})\end{array}$ & - & $\begin{array}{l}2 \cdot 32 \\
\text { (NS) }\end{array}$ & - & - \\
\hline Sperm count & $\begin{array}{r}1.54 \\
(\mathrm{NS})\end{array}$ & $\begin{array}{r}0.22 \\
\text { (NS) }\end{array}$ & - & $\begin{array}{c}4.55 \\
(P<0.05)\end{array}$ & - & - \\
\hline Body wt & $\begin{array}{r}3.80 \\
(\mathrm{NS})\end{array}$ & $\begin{array}{c}12.26 \\
(P<0.01)\end{array}$ & $\begin{array}{c}196.9 \\
(P<0.001)\end{array}$ & $\begin{array}{l}0.84 \\
\text { (NS) }\end{array}$ & $\begin{array}{c}9.8 \\
(P<0.001)\end{array}$ & $\begin{array}{c}13.8 \\
(P<0.001)\end{array}$ \\
\hline
\end{tabular}



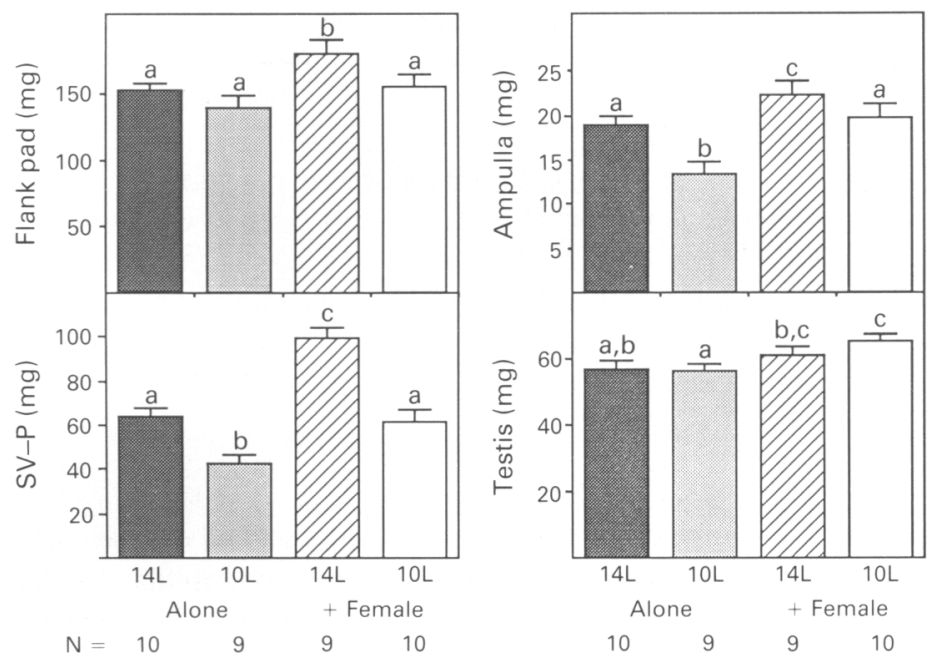

Fig. 2. Values for the androgen-sensitive target tissues (SV-P $=$ seminal vesicle-prostate) collected in Exp. 2 are shown as the mean \pm s.e.m. Males were placed into treatment groups at weaning ( 20 days of age). Values with different letters indicate values significantly different from each other $(P<0 \cdot 05)$.

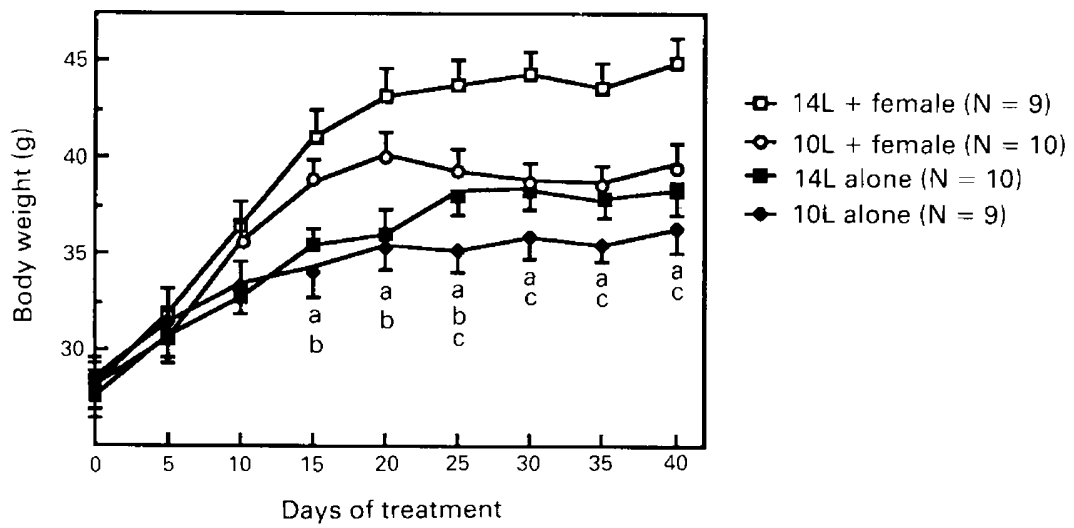

Fig. 3. Growth curves from Exp. 2 are shown as the mean \pm s.e.m. $P<0.05$ for (a) female $v s$ alone for 14L:10D, (b) female vs alone for 10L:14D and (c) 14L:10D vs 10L:14D for + female.

Although significant differences between the groups were not always evident from analysing the main effects, comparison of group means revealed further significant effects of photoperiod and social cues on the physiological parameters measured. Short days inhibited growth of the seminal vesicle-prostate complex, ampulla and flank pad in males living alone (10L:14D alone vs 14L:10D alone), as well as in those living with a female (10L:14D + female vs 14L:10D + female). In addition, cohabitation with a female stimulated growth of the seminal vesicle-prostate complex and ampulla in males kept in short days (10L:14D + female vs 10L:14D alone), as well as stimulating growth of these 2 tissues and the flank pad in animals kept in long days (14L:10D + female vs 14L:10D alone). There were no differences in weights of the seminal vesicle-prostate complex, ampulla or flank pad between males in the 14L:10D alone group and those in the 10L:14D + female group. The testis was only marginally responsive to treatment. Specifically, both the 
14L:10D + female group and the 10L:14D + female group had greater testis weights than the 10L:14D alone group; however, there were no significant differences in testis weights between the 2 groups housed alone, or between the 2 groups housed with a female. Finally, there were no significant differences in the number of spermatozoa/testis between any of the treatment groups (data not shown). The effects of photoperiod and social cues on body weight followed a pattern similar to that for reproductive development. Males kept in long days with a female had the greatest body weights, while those kept in short days and alone had the lowest body weights. Furthermore, by 25 days of treatment males kept in short days with a female had intermediate body weights, as did males kept in long days and alone.

\section{Experiment 3: combined effects of photoperiod and social cues in adults}

In general, exposure to $10 \mathrm{~h}$ light/day had inhibitory effects and the presence of an adult female had stimulatory effects on both the reproductive physiology and body growth of adult males. The pattern of response in the adult to photoperiod and social cues was similar to that seen in juvenile males. The main effects of photoperiod and social cues on the weights of the androgen-sensitive target tissues, sperm count and body weight are shown in Table 3, while specific differences between group means are indicated in Fig. 4. There was a main effect of photoperiod on both testis and ampulla weights. Furthermore, there was a main effect of social cues on body weight. Comparisons of group means revealed more extensive effects of photoperiod and social cues on the measured variables. Short days reduced the weights of the seminal vesicle-prostate complex, ampulla and flank pad in males living alone (10L:14D alone vs 14L:10D alone), as well as reducing the weights of these tissues and the testis in those animals living with a female (10L:14D + female vs 14L:10D + female). In addition, cohabitation with a female enhanced weight gain of the seminal vesicle-prostate complex and ampulla in males kept in short days (10L:14D + female vs 10L:14D alone), as well as enhancing weight gain of the seminal vesicle-prostate complex in animals kept in long days (14L:10D + female vs 14L:10D alone). There were no differences in weights of the seminal vesicle-prostate complex, ampulla or flank pad between males in the 14L:10D alone group and those in the 10L:14D + female group (however, testis weight was lower in the 10L:14D + female group). Body weights of males in the 14L:10D + female group were greater than those in the 2 groups of males kept alone.

Table 3. Analysis (F values, with $P$ values in parentheses) of main effects of photoperiod and social cues in adult males (Exp. 3)

\begin{tabular}{llll}
\hline & Photoperiod & Social cues & Interaction \\
\hline Seminal vesicle- & & & \\
$\quad$ prostate complex wt & $2.49(\mathrm{NS})$ & $3.06(\mathrm{NS})$ & $0.42(\mathrm{NS})$ \\
Ampulla wt & $5.06(P<0.05)$ & $2.41(\mathrm{NS})$ & $0.28(\mathrm{NS})$ \\
Flank pad wt & $0.72(\mathrm{NS})$ & $1.09(\mathrm{NS})$ & $0.41(\mathrm{NS})$ \\
Testis wt & $4.79(P<0.05)$ & $0.001(\mathrm{NS})$ & $0.74(\mathrm{NS})$ \\
Body wt & $3.72(\mathrm{NS})$ & $7.83(P<0.01)$ & $0.71(\mathrm{NS})$ \\
\hline
\end{tabular}

\section{Discussion}

The results from the present studies demonstrate that photoperiod and social cues have independent and integrative effects on the reproductive physiology of the male musk shrew. Data collected in Exp. 2 showed that presence of an adult female could partly override inhibitory effects of short days on reproductive maturation and body growth in juvenile males; in Exp. 3, adult males showed 

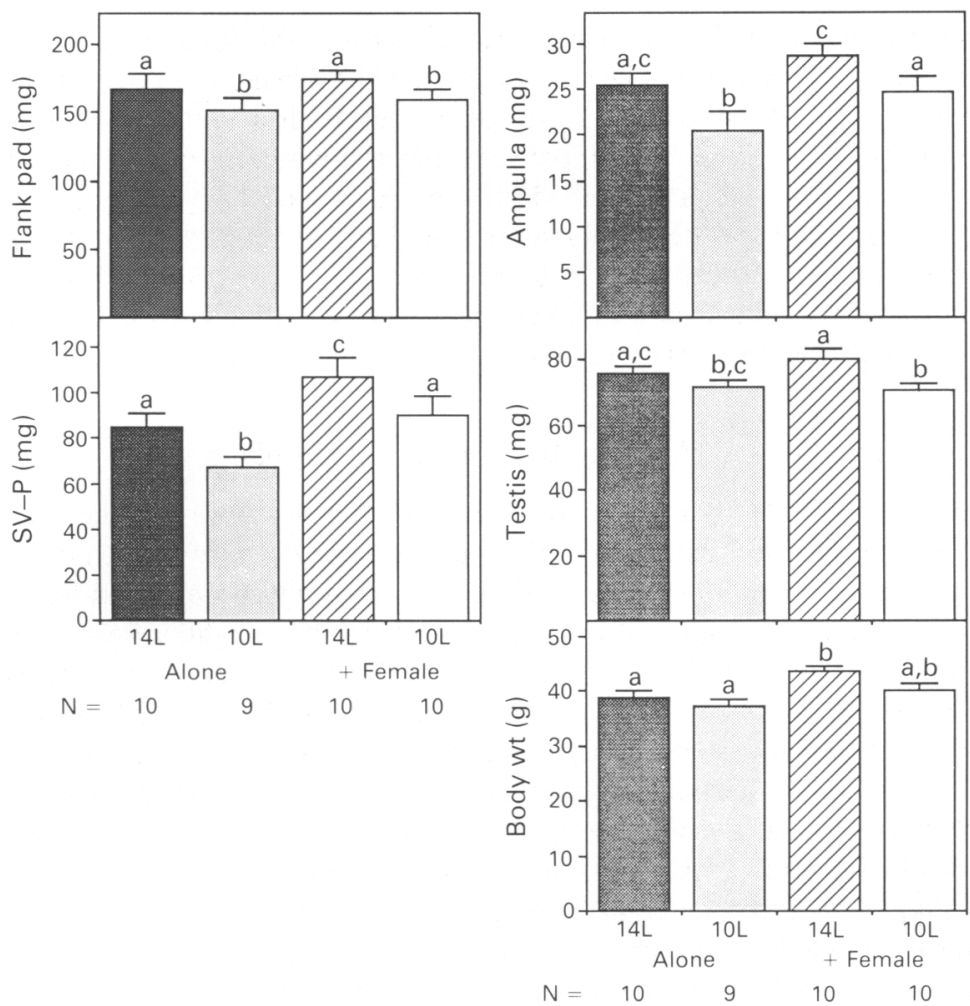

Fig. 4. Values for the androgen-sensitive target tissues (SV-P $=$ seminal vesicle-prostate) and body weight from Exp. 3. Males were placed into treatment groups at 60 days of age. Values with different letters indicate values significantly different from each other $(P<0.05)$.

a similar response. Specifically, cohabitation with a female stimulated growth of a number of androgen-sensitive target tissues. Males kept with a female in short days showed a greater level of reproductive function than did those kept alone in short days. Furthermore, this stimulatory effect of the female resulted in a comparable level of reproductive function between males kept with a female in short days and those kept alone in long days. However, this inductive effect of the female could not completely block the inhibitory effects of short days because males kept in long days with a female had a greater level of reproductive function than did those kept in short days with a female.

In addition, the body weight response to both photoperiod and social cues paralleled the reproductive response; short days suppressed whereas presence of a female enhanced body growth. As with sexual maturation in juvenile males, cohabitation with a female partly blocked the inhibitory effects of short days such that animals kept with a female in short days had greater body weights than did those kept alone in short days. These changes in body weight, however, cannot solely account for short-day inhibition and female stimulation of sexual maturation because the data analysis factored-out influences of body weight on the weights of the reproductive tissues (see 'Materials and Methods'). This suggests that body growth and reproductive development are affected independently by photoperiod and social cues. This point is more obvious in other species such as the deer mouse in which photoperiod and social cues have no effect on body growth but do affect reproductive development (Whitsett \& Lawton, 1982; Garcia \& Whitsett, 1983).

Modulation of photoperiodic responses by social cues has been demonstrated in several rodent species which are seasonal breeders (hamster: Vandenbergh, 1977; Davis et al., 1987; Matt \& 
Morgan, 1989; field vole: Spears \& Clarke, 1986; deer mouse: Whitsett \& Lawton, 1982; Garcia \& Whitsett, 1983). For instance, in female deer mice, cohabitation with an adult male stimulated pubertal development in animals reared in short days (Garcia \& Whitsett, 1983). Moreover, levels of reproductive maturation were comparable between females housed with a male in short days and those housed alone in long days. Garcia \& Whitsett (1983) suggested that the presence of a male could compensate for the absence of an inductive photoperiod in regulating pubertal development in female deer mice. In the present study with male musk shrews, we saw a similar sort of 'compensation' in which the presence of an adult female stimulated sexual maturation to that level achieved in isolated males reared in long days.

The results from Exp. 1 showed that an increase in daylength at weaning, from $14 \mathrm{~L}$ to $18 \mathrm{~L}$, did not accelerate reproductive maturation or body growth. We know from Exps 2 and 3 that shrews raised in 14L:10D were capable of further reproductive stimulation by the presence of an adult female. Therefore, the limiting factor in advancing sexual maturation in Exp. 1 was an insensitivity to a 4-h increase in daylength and not an insensitivity of the reproductive system to further stimulation. It is possible that the animals raised in $14 \mathrm{~L}: 10 \mathrm{D}$ had received maximal photoperiodic stimulation. Alternatively, further reproductive stimulation may have required an increase in photoperiod of greater than $4 \mathrm{~h}$.

The present results showed that environmental treatment had little or no effect on testicular weight and the number of spermatozoa/testis. This testicular insensitivity to both photoperiod and social cues can be interpreted in light of the fact that the musk shrew is a short-lived opportunistic breeder found in relatively mild climates. Bronson (1985) suggested that, for such an animal, the greatest genetic advantage is to be in a state of readiness when favourable environmental conditions occur. In the adult musk shrew, full spermatogenic activity requires approximately 60 days for completion (Singh, 1983, 1984). Therefore, the period between collapse of the testis and its redevelopment, as well as reactivation of spermatogenic activity, would be too long a time for rapid responses to local environmental changes. If the gonads are at least partly active, then the animal may attain reproductive competence soon after the onset of inductive signals.

The most relevant environmental signals for regulating reproductive activity in short-lived opportunistic breeders are factors such as social cues, ambient temperature and food availability (Bronson, 1985). The present findings, as well as those of Rissman et al. (1990), showed that juvenile male musk shrews are highly responsive to the presence of an adult female. It is not yet known which specific signals from the female stimulate sexual maturation in the male musk shrew. Females living across a wire mesh barrier from males for 40 days stimulated sexual maturation to the same extent as did full contact between the sexes. Exposure to cage-bedding soiled by adult females had little effect on sexual maturation, while absence of visual contact between male-female pairs reduced the inductive effect of the female (Rissman et al., 1990). These results suggest that non-volatile pheromones alone are not sufficient to accelerate sexual maturation, and yet sexual maturation was affected when pairs were separated by a wire screen. There may therefore be some synergistic interactions between pheromones, visual and/or auditory cues.

The relative importance of photoperiodic cues in regulating sexual maturation in the musk shrew have been unclear given the natural history of the animal (see Rissman et al., 1987). The animals used in our studies came from a stock trapped on Guam Island in the early 1960s. Guam lies $13^{\circ} \mathrm{N}$ latitude where the annual change in photoperiod is $1.5 \mathrm{~h}(13 \mathrm{~h} \mathrm{light} /$ day on summer solstice, $11.5 \mathrm{~h} \mathrm{light/day} \mathrm{on} \mathrm{winter} \mathrm{solstice).} \mathrm{The} \mathrm{shrews} \mathrm{in} \mathrm{the} \mathrm{present} \mathrm{study} \mathrm{clearly} \mathrm{res-}$ ponded to a 4-h decrease in daylength. Our recent work provides evidence that juvenile males are very sensitive to small changes in photoperiod of $1.5 \mathrm{~h}(\mathrm{~N}$. L. Wayne \& E. F. Rissman, unpublished observations). These results suggest that male musk shrews may, in their natural habitat, use photoperiodic information to alter the timing of puberty. We can speculate that the shrew is highly sensitive to small changes in photoperiod and that this information alters the degree of responsiveness to environmental variables such as social cues, food availability and predation pressure. 
We thank Ms Susan Taymans and Ms Susan Harlow for technical assistance; Dr Eric Turkheimer for advice and help with the statistical analyses; and Dr Fred Karsch for critical evaluation of an earlier version of the manuscript. Supported by NSF grant BNS 8706770 and NIH grants 5T32-MH-18411 and MH-45495.

\section{References}

Barbehenn, K.R. (1962) The house shrew on Guam. In Pacific Island Rat Ecology: Report of a Study Made on Ponape and Adjacent Islands, pp. 247-256. Ed. T. I. Storer. Bernice P. Bishop Museum, Bulletin 225, Honolulu.

Beg, M.A., Kauser, S., Hassan, M.M. \& Khan, A.A. (1986) Some demographic and reproductive parameters of the house shrew in Punjab (Pakistan). Pakistan J. Zool. 18, 201-208.

Bronson, F.H. (1985) Mammalian reproduction: an ecological perspective. Biol. Reprod. 32, 1-26.

Davis, F.C., Stice, S. \& Menaker, M. (1987) Activity and reproductive state in the hamster: Independent control by social stimuli and a circadian pacemaker. Physiol. Behav. 40, 583-590.

Garcia, I.M.P.S. \& Whitsett, J.M. (1983) Influence of photoperiod and social environment on sexual maturation in female deer mice (Peromyscus maniculatus bairdii). J. comp. Physiol. 97, 127-134.

Harrison, J.L. (1955) Data on the reproduction of some Malayan mammals. Proc. Zool. Soc. Lond. 125, 445-460.

Kirton, K.T., Desjardins, C. \& Hafs, H.D. (1967) Distribution of sperm in male rabbits after various ejaculation frequencies. Anat. Rec. 158, 287-292.

Louch, C.D., Ghosh, A.K. \& Pal, B.C. (1966) Seasonal changes in weight and reproductive activity of Suncus murinus in West Bengal, India. J. Mammal. 47, 73-78.

Matt, K.S. \& Morgan, S.R. (1989) Neural processing of environmental information in the Siberian hamster (Phodopus sungorus). Proc. 19th Ann. Mtg Soc. Neurosci., Phoenix, Abstr. 375.3.
Rissman, E.F., Nelson, R.J., Blank, J.L. \& Bronson, F.H. (1987) Reproductive response of a tropical mammal, the musk shrew (Suncus murinus), to photoperiod. $J$. Reprod. Fert. 81, 563-566.

Rissman, E.F., Taymans, S.E. \& Wayne, N.L. (1990) Social cues influence growth and sexual maturation of a tropical mammal, the musk shrew (Suncus murinus). J. Reprod. Fert., 89, 697-706.

Singh, S.K. (1983) Effect of clomiphene citrate on the testis, epididymis and accessory sex glands of the musk shrew. Annls Endocr. 44, 131-138.

Singh, S.K. (1984) Effect of flutamide on the testis and accessory sex glands of the musk shrew, Suncus murinus L. Exp. clin. Endocrinol. 84, 20-26.

Spears, N. \& Carke, J.R. (1986) Effect of male presence and of photoperiod on the sexual maturation of the field vole (Microtus agrestis). J. Reprod. Fert. 78, 231-238.

Turek, F.W. \& Campbell, C.S. (1979) Photoperiodic regulation of neuroendocrine-gonadal activity. Biol. Reprod. 20, 32-50.

Vandenbergh, J.G. (1977) Reproductive coordination in the golden hamster: female influences on the male. Horm. Behav. 9, 264-275.

Whitsett, J.M. \& Lawton, A.D. (1982) Social stimulation of reproductive development in male deer mice housed on a short-day photoperiod. J.comp. Physiol. Psychol. 96,416422 .

Received 5 December 1989 